\title{
A Review of Design and Implementation of Hydrogen Fuel Cell with Modified Proton Exchange Membrane
}

\author{
${ }^{1}$ D V.Manjunatha, ${ }^{2}$ Richard Pinto, ${ }^{3}$ Shreya S Poojary, ${ }^{4}$ Veronica Gudagur, ${ }^{5}$ Bhavya G B \\ Department of Electronics and Communication Engineering, Alvas Institute of Engineering and Technology, \\ Mangalore, India.
}

\begin{abstract}
Hydrogen fuel cells use hydrogen and oxygen as fuel which is converted into electricity and water. This is similar to batteries we commonly use in which chemical energy is converted to electricity. The batteries contain all of the essential chemicals within and when the chemical supply is reduced, they seize to function. On the other hand, fuel cells require a continuous supply of fuel for operation. Proton exchange membrane fuel cells (pemfes) are able to generate clean power. Proton exchange membranes (pems) are the main components of pem fuel cells. In this paper the authors focus on high proton conductivity, low fuel permeability, low electro osmotic drag coefficient, good chemical/thermal stability, and high power efficiencies. These are classified into the "iron triangle" performance, durability and cost. Current pemfe technology is based on expensive perflourinated proton exchange membranes that only operate efficiently under fully hydrated conditions. There is important requirement for reducing the membrane and catalystcosts.
\end{abstract}

Keywords-Proton exchange membrane fuel cell, platinum catalyst, nafion membrane, comsol multiphiciscs.

\section{INTRUDUCTION}

A fuel cell is a device that converts chemical energy (energy stored in the form of molecular bonds) into electrical energy. Proton Exchange Membrane (PEM) uses hydrogen gas and oxygen gas as fuel. This reaction leads to production of electricity, water and heat as byproducts. $\mathrm{O} 2$ is readilyavailable in the atmosphere and hence, there no need to supply oxygen and the fuel cell will be air-breathing; we need to supply only H2. In this process PEM electrolysis has been used to get electricity ${ }^{[2]}$.

During the electrochemical reaction of hydrogen and oxygen, a proton exchange membrane fuel cell generates electrical energy due to conversion of chemical energy, as opposed to the direct combustion of hydrogen and oxygen gases to produce thermal energy. A stream of hydrogen is delivered to the anode side of membraneelectrode-assembly (MEA). Catalytically, on the anode side it is split into protons andelectrons.

PEM fuel cell consists of four basic elements. The basic elements of PEMFC are shown in Figure 1. Cathode is positive part of the fuel cell which has channels that distribute oxygen to the surface of the catalyst. It also conducts the electrons present in the external circuit back to the catalyst where water is produced with the recombination of protons and oxygen ions.

Anode is the negative part of the fuel cell. It conducts the electrons that are generated at the anode catalyst into the external circuit thus generating electric power. The micro channels in the anode and cathode, flow hydrogen and oxygen gas, respectively. They help to spread the hydrogen gas equally over the surface ofcatalyst.

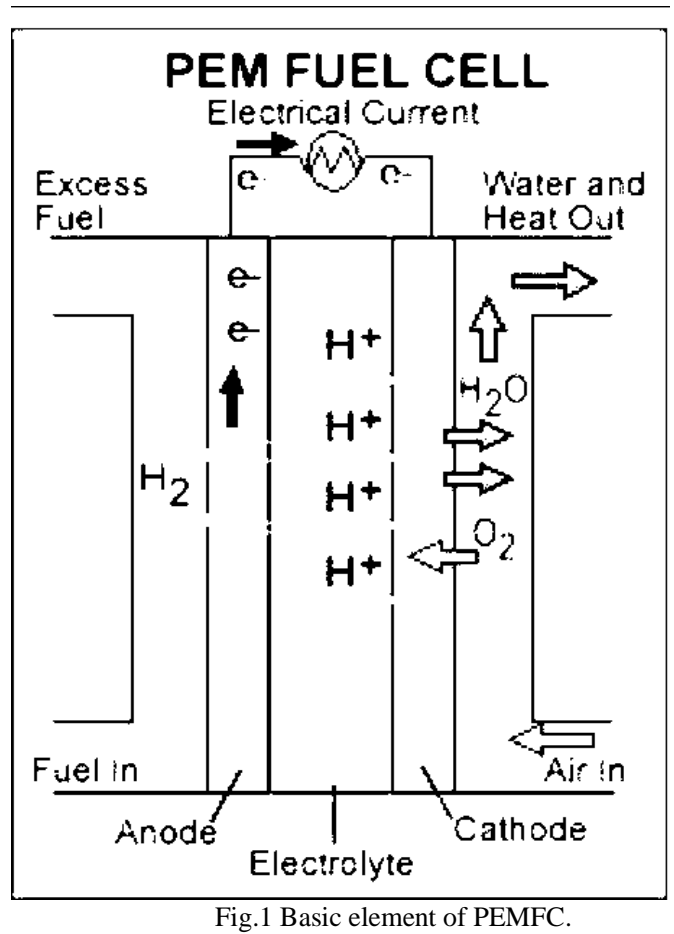

The electrons travel to the cathode side of the MEA from external load circuit. It creates energy output of the fuel cell. Oxygen stream is delivered to the cathode side of the MEA. Here oxygen ions and protons permeated through the membrane from the anode side react to form water molecule.

Short circuit of fuel is the transport of fuel through the membrane before conversion into protons and generation of electrons which pass to the external circuit. This is known as fuel cross-over. Fuel cross-over leads to short circuit effect in HFCs and lowers their performance.Finally, the membrane must be resistant to changes during operation and should be stable. Platinum 
catalyst is used at the anode to form protons that diffuse through the membrane to cathode side. which generates oxygen ions, thus facilitating reaction to generate water. Platinum has been found to be the best catalyst in fuel cells.

\section{LITERATURESURVEY}

Review of Literature is a significant part of the project. It allows assimilation of the knowledge required for the project right from the description of the problem, finding a solution and its implementation. The following report summarizes the review of literature conducted for the project.

Staff ell et al[1] addressed the function of the hydrogen fuel cell in a global energy system. This paper gives a detailed analysis of the possible role of hydrogen may have in generation of electricity. This survey shows that challenges in efficiency and performance remain, and significant improvements are still needed to make hydrogen fuel cells truly competitive.

Mubin[2] discussed the proton exchange membrane fuel cell (PEMFC) which has gained importance because of its efficiency of power conversion and zero emission. PEMFC has a high energy conversion efficiency of 50 to $60 \%$; also if hydrogen is used it is renewable and is a clean energysource.

Runge et al[3] surveyed that Hydrogen has many advantages over methane or natural gas. Experimentally, hydrogen fuel cells have been explored for automobiles because it is a clean energy source and has high conversion efficiency. The main problem now is storage of hydrogen and the cost ofHFCs.

Dodd et al.[4] surveyed that hydrogen can play a major role in the low-carbon electricity economy. Electricity has to rapidly become carbon free and HFCs will contribute greatly in this goal. Hydrogen holds the same versatility and allows for deeper decarburization by offering low carbon stability andstorage.

Conte et al[5] discussed that hydrogen is an energy carrier which is available in the environment; it can be formed from different sources, renewable and fossils. Further, hydrogen can be stored more easily than electricity and can be used in many applications, essentially without emitting harmful effluents in the environment. Fuel cells are the best technology to use hydrogen in transport and distributed power generation areas with negligible effect on the environment and with high efficiency.

Sharma et al.[6] discussed that hydrogen is an important fuel for transport. This is the least polluting fuel available and it can be generated wherever water and a clean source of electricity are present. A fuel cycle in which hydrogen is produced by solar water electrolysis and then used in an electric motor vehicle powered by hydrogen fuel cells is the most attractive fuel cycle.

Rubio et al.[7] surveyed that hydrogen is not found to be chemically free in the environment; it is present as Compound like water on Earth. At present, world's leading energy source, that is, electricity receives its fuel mainly from fossil sources. Hydrogen is also an energy carrier of high quality that can be stored and delivered as usable energy sources similar to electricity produced by chemical processes and a variety of sources. Not only can hydrogen be used in fuel cells to generate electricity, it can also be used inside the ignition appliances to fuel petrochemicals, such asdiesel.

Gutiérrez et al [8] observed that hydrogen is produced in industrial plants as a by-product and that hydrogen produced from liquefied petroleum gas and natural gas is used for energy drives. HFCs are expected to be more efficient, environmental friendly and eventually would reduce the cost of transportation once low cost HFCs are produced in a large scale.

Pooja et al.[9] surveyed that hydrogen is the simplest element on the globe and, despite its abundance and simplicity, has problems in storage as a pure gas. Hydrogen is often not naturally known to exist as a gas. It exists mostly in combination oxygen as water. And hydrogen is also available with other elements, for example, in many organic compounds particularly the "hydrocarbons," the type of fuels such as natural gas, gasoline, methanol and propaneetc.

Estela et al.[10] surveyed that hydrogen can be generated from a range of primary sources. Today, hydrogen is extracted mainly from fossil fuels through a process known as "steam reforming;" most fuel cell and renewable energy supporters are uncomfortable with the idea of steam reforming hydrogen because carbon dioxide $(\mathrm{CO} 2)$ is a by- product of the procedure. Environmentalists argue that hydrogen should be made from clean water and sustainable solar energy, as well as "cleaner" nuclear energy including fusion, to truly reap the benefits of environmentally friendly characteristics. Others disagree, citing that natural gas hydrogen would also reduce emissions by up to 40 per cent. This, assert natural gas supporters, proves that society should not wait for purely renewable hydrogen energy to make significant greenhouse emission cuts. In contrast, natural gas proponents claim that this will act as a bridge to a society with hydrogen and renewableenergy.

Yuan and Wang[11] have observed that PEMFCs use a quasi-solid electrolyte based on a polymer backbone with side chains having acid-based groups, unlike the main other types of fuel cells. The many advantages of electrolytes make the PEM fuel cell especially useful for smaller applications such as homebased distribution and transportation and portable power 
applications. PEMFC features provide relatively high power density,low temperature operation, a compact system, and simplicity in fuel usage.

Hocevar et al[12] consider that hydrogen is not only the toughest chemical fuel, it also works as a transporter for energy. Hydrogen can be produced in various ways and then used for moving energy over long and short distances or for processing energy into heat and electricity on-site. The objective is explicitly on those ways to produce hydrogen that are sustainable (like biomass) or, better even, renewable like solar, wind, geothermal, hydro etc.

Mahmoud et al.[13] surveyed that the Proton exchange membrane fuel cell based on very thin polymer membrane as an electrolyte and suggested that it will be an important candidate of future power sources, especially for transport and residential powerpurposes. This type of fuel cell has some important advantages such as clean operation, high efficiency, operation at lower temperature, quick start, no liquid electrolyte and simple cell design.

Dincer et al[14] discussed hydrogen tanks from a vast array of sources, such as fossil hydrocarbons, water, biomass, hydrogen sulphide, boron hydrides and others. Energy generation methods and hydrogen production methods can be divided into four types: thermal, electric, photonic, and biochemical. These forms of energy can be found in fossil, nuclear, and renewable energy.

Garus and Polak[15] surveyed some types of fuel cells, each using a different electrolyte to isolate the electrodes in the fuel cells. Proton exchange membrane fuel cell (PEM FC), also known as the polymer exchange membrane fuel cell, which uses hydrogen, has the widest possible applicability. It has many advantages.. The most important advantages are: operation at relatively low temperatures, maintaining maximum efficiency, rapid start- up and zero emission and hence, no pollution. The fuel cell requirements are hydrogen fuel and oxidant, which is oxygen in the case of PEMFCs and they generates heat, water and electricity as a reactionproduct.

Shen[16] observed that Proton exchange membrane fuel cells, due to their applicability to portable electronic products and transport systems, must involve a detailed response. For these the main challenges in PEMFC research are heterogeneous and complex, especially involving catalyst layers. It is essential to design the catalyst layers to produce high rates of conversion of hydrogen into protons and also conversion of oxygen onto oxygen ions. Hence, initially the cost of PEMFCs is going to be high.

Daletou et al[17] surveyed that the polymer electrolyte membrane fuel is considered as the most promising one and hence, has earned increased attention due to the advantage of less corrosion arising from the solid structure as a whole. For various applications, the PEM fuel cells are considered best as they offer fast startup, high performance, mechanical simplicity, versatility and modularity. The design of a PEM fuel cell consists of a polymeric membrane which also has unique capabilities.The fuel cell membrane in particular must have relatively high proton conductivity, and in the challenging fuel cell environment, it must be chemically and mechanically stable and should have very low hydrogen cross-over.

Barbir[18] observed that Proton exchange membrane fuel cells are now very promising as a source of electricity for many transport applications. PEM fuel cells have no moving parts, have smooth operation, do not

produceanyemissions, areveryefficient(usuallyabout50 $\%$ ), operate in relatively mild operating conditions (temperatures up to $90^{\circ} \mathrm{C}$ and pressures up to $600 \mathrm{kPa}$ ) and are extremely sensitive to changes in load. Thus, the technology needs further development from the performance, reliability, processing and costaspect.

Shen et al[19] discussed that PEMFCs can be used as a power source in applications such as transportation and are the most promising energy converters in terms of low or zero emissions, high efficiency and high power density. In order to realize low cost PEM fuel cells over the last few decades, great effort has been made in finding ways to reduce cost of production.

Ewe[20] observed the chemical energy of bonding hydrogen and oxygen is transformed directly into electrical energy in proton exchange membrane fuel cells, without the intermediate step of extracting the heat energy. However, the fuel cells are not immune to the Camot factor. The cell performs the combination of hydrogen and oxygen into the overall reaction to form water with anodic hydrogen conversion into protons and electrons and cathodic oxygen combination with protons to formwater.

\section{CONCLUSION}

PEMFCs, especially HFCs are promising due to a variety of reasons: High efficiency conversion of hydrogen and oxygen to form water which is a clean byproduct, low noise operation, mechanical stability and easy transportability. However, the main problem currently is the high cost of production primarily due to the high cost platinum catalyst. Hence, lot of research work needs to be carried out by reducing the amount of platinum catalyst, or finding an alternate low cost catalyst. The cost of present nafion membrane is also relatively high. However, due to the great advantage of being a clean energy source, HFCs will eventually become an important energy source for transportation and also for stationaryapplications. 


\section{REFERENCES}

[1] Iain Staff ell , Daniel Scamman , b Anthony Velazquez adabPaul Balcombe, c Paul E. Dodds, Bpaul Ekins, bNilayShahd and kate R, warda : energy Environ. 2019 Sci., 12,463.

[2] R.N.A. Mubin IOP Conf2017 Ser.: Mater Mater Science:Math.Ing.2010012052.

[3] Runge, Jeffery W., Sae J2578: Recommended general Fuel cell vehicle safetyActivities.

[4] E.P. Dodds.(Eds.) (2107) The role of fuel cells and hydrogen in future energy systems. Sci., 2019: 12,293. H2FC SUPERGEN, UK forLONDON.

[5] Mario Conte , ENEA, C.R. Casaccia, Energy Technologies, Renewable energy Sources and energy saving dept. By means of Anguillarese,301,00123 S.M. Di Galeria(Italy),Rome.

[6] Ravi Kumar Sgarma, MTech (automobile Eng.,), University of Bharath, Chennai-600073, India. International Journal of engineering and Advanced Technology (IJEAt) ISSN: 2249-8958, volume 4,Issue 4, April2015.

[7] Mary Grace A. Rubio and KitipongJaojaruek Mechanical Engineering School, Faculty of Engineering in kamphaengSaen, University of Kasetsart, Thailand. Jaojaeuek and Rubio AdvAutomobEng 2015, 4:1 DOI: 10.4172/2167- 7670.1000116.

[8] Juan A. Cabrera, Felipe Rosa, Fernando Isorna INTA, Ctra, Marina Gutierrez, Eduardo Lopez. S. JuanMatalascanas, km. 33 Mazagon(Huelva), Spain, 21130. Power 2009,2, 150179: DOI: 10.3390/20100150.

[9] Pooja Kitten, MTech. ECE, S.S.C.E.T, Badhani, Pathankot, Panjab, India. Vol.2, Issue 11, November 2013.

[10] November 29, 2001, Wendy Estela Pace University School of Law Environmental science foe Lawyers. Sci.,2019,12.

[11] NRC-IFCI: Xiao-Zi Yuan and Haijiang Wang; 2005. File No.:CTR-015-IFCI-PEMFC.

[12] R. StankoHo et William summers A. Leon(ed.), Hydrogen technology, 15 cBerlinheidelbergSpingerVerlag2008.

[13] Nader Pourmahmoud1, Sajad Rezazadeh2, *, Iraj mirzaee1 and SonitalMotaleb Faed1 1 Department of MechanicalEngineering,uremiaUniversityofTechnology,UrmiaIran 2CFD Research Center, department of Mechanical Engineering, Urmia University of Technology, Urmia, Iran (Manuscript Received 2 July 2011; Reversed 27 November

2011; Accepted 13 march 2012).

[14] Dincer and C. Zamfiresru, Applications and Sustainable Electrical systems, DOI 10.1007/978-0-387-95861-3 13, \# Spinger science + Business Media, LLC2011.

[15] Adam Polak and Jerzy garus Polish Naval Academy, Gdynia, Poland@ Spinger International; Publishing Schwerin 2015 J. Awrejcewicz et al.(eds.), Mechatronics : Intelligent Systems and Computing Ideas for Industrial Applications , 317Advances, DOI:10.1007/978-319-10990-94

[16] Pei Kang ShenApplElectrochem1992;22:17.

[17] Cabo, Maria K. Daletuo, Joannis Kallitsis, and Stylianos G. NeophytidesC.G.Vayenas(ed.), Electromagnetically Interfacial. Phenomena, Modern Molecular Aspects 51, DOI 10.1007/978-1-4419-5580-7-6.

[18] North point Parkway, Suite 102 West palm Beach, FL 33407, Y. Yiiriim (ed.), Hydrogen Energy System,203-213. \#1995 Kluwer Academic Publishers.

[19] Jun shen N. Pour Mahmoud Stylianos G Mechanical Science andTechnology Journal 26(9)(2012)2959 2968.

[20] Prof. H.Ewe, Hamburg. Europe's. W.Justi, A Solar Paneling. 